\title{
Comparisons of cryptococcal meningitis caused by Cryptococcus neoformans between HIV-negative patients with and without lung infection in two Chinese university hospitals
}

\section{Ming Yang}

Third Military Medical University Southwest Hospital Department of pharmacy

\section{Fengjun Sun}

Third Military Medical University Southwest Hospital Department of Pharmacy

Fu Liu

North Sichuan Medical University

\section{Wei Feng}

Third Military Medical University Southwest Hospital Department of Pharmacy

Qian Yuan

Third Military Medical University Southwest Hospital Department of Pharmacy

\section{Yu Wang}

Third Military Medical University Southwest Hospital Department of Pharmacy

\section{Lin Cheng ( $\square$ cheng7zhu@163.com)}

Department of Pharmacy, the First Affiliated Hospital of Army Medical University https://orcid.org/0000-0003-3825-5378

\section{Peiyuan Xia}

Third Military Medical University Southwest Hospital Department of Paharmacy

\section{Research article}

Keywords: Cryptococcal meningitis, Cryptococcus neoformans, Lung infection, Clinical characteristics, Diagnosis

Posted Date: September 12th, 2019

DOl: https://doi.org/10.21203/rs.2.14341/v1

License: (c) (i) This work is licensed under a Creative Commons Attribution 4.0 International License. Read Full License 


\section{Abstract}

Background Lung infection may cause many symptoms, such as fever and headache, that may be confused with cryptococcal meningitis (CM) symptoms. This study aimed to investigate the discrepancy in clinical features and outcomes of CM between HIV-negative patients with and without lung infection.

Methods We retrospectively reviewed the medical records of patients with $\mathrm{CM}$ admitted to two hospitals in Southwest China from 1 January 2014 to 31 December 2018.

Results A total of 71 patients was included during the 5 years, among which 35 (49.3\%) patients had lung disease. CM occurred more frequently in male ( $62.9 \%$ vs. $44.4 \%, P=0.12)$ and young ( $\leq 30$ years, $31.4 \%$ vs. $16.7 \%, P=0.30$ ) patients with lung infection than in the patients without lung infection, with more fever ( $77.1 \%$ vs. $30.6 \%, P=0.001)$ and less central nervous system symptoms $(5.7 \%$ vs. $16.7 \%, P=0.28)$ and vomiting $(25.0 \%$ vs. $14.3 \%, \mathrm{P}=0.26)$. In addition, patients with lung infection presented higher percentages of white blood cell (WBC) counts $₫ 20 \times 106 / L(45.7 \%$ vs. $22.2 \%, P=0.036)$ and lower percentages of ethmoid sinusitis, maxillary sinusitis, paranasal sinusitis, and otitis media than patients without lung infection ( $8.6 \%$ vs. $30.6 \%, \mathrm{P}=0.02)$. The Cryptococcus neoformans isolates were sensitive to itraconazole, voriconazole, fluconazole, and amphotericin B but resistant to flucytosine. Patients with lung infection had higher mortality at discharge compared with patients without lung infection ( $8.6 \%$ vs. $0, P=0.12)$. Multivariable analyses showed that WBC counts $₫ 20 \times 106 / \mathrm{L}$ was significantly associated with treatment outcome (OR=0.01, 95\% Cl=0-0.833, $\mathrm{P}=0.041)$.

Conclusions There were significant discrepancies in clinical features between CM patients with and without lung infection. Clinicians must consider the divergences in the diagnosis of $\mathrm{CM}$ in patients with lung infection.

\section{Background}

Cryptococcal meningitis (CM) caused by Cryptococcus neoformans is a common opportunistic infection, the main cause of mortality in human immunodeficiency virus (HIV)-infected patients, and increasingly observed among patients with non-HIV immunosuppression [1, 2]. Mortality outcomes for CM in HIVnegative individuals seem to be no better than those in HIV-positive patients [3-5]. Lung infection is a common disease that can be caused by many pathogens, such as Streptococcus pneumoniae, Staphylococcus aureus, Klebsiella pneumoniae, Haemophilus influenza, Pseudomonas aeruginosa, Mycoplasma pneumonia, and fungi; lung infection may cause many symptoms, such as fever and headache, that may be confused with central nervous system (CNS) infection. In immunosuppressed individuals, infection begins in the lung after inhalation of fungal spores and often spreads to other organs, particularly the brain [6]. Many CM patients also have concomitant lung involvement, which is often overlooked or misdiagnosed as tuberculosis [7].

The clinical characteristics and outcomes in $\mathrm{CM}$ have been shown to vary depending on the underlying condition [8-14]. The HBV-positive CM patients presented with lower initial complaints of visual 
symptoms, lower cerebrospinal fluid (CSF) white blood cell (WBC) counts, lower percentages of the total protein in the CSF exceeding $0.45 \mathrm{~g} / \mathrm{L}$, higher glucose levels in the CSF, higher percentage of positive results for Cryptococcus culture in the CSF, more extraneural involvement sites, and a higher proportion of normal brain images compared with the HBV-negative CM patients [14]. Compared with the immunocompromised patients, $\mathrm{CM}$ was present in a younger population, with higher initial complaints of visual and auditory symptoms, higher CSF WBC counts, higher proportion of normal brain images in the immunocompetent patients [11]. In addition, the elderly patients ( $\geq 65$ years) were more vulnerable to $\mathrm{CM}$ than adults aged $<65$ years, and had female predominance, higher rates of altered consciousness and recent cerebral infarction [15]. Therefore, HIV-negative patients with lung infection but with CM tend to present with atypical features, which can lead to significant delays in their diagnosis and poorer outcomes.

There are many HIV-negative CM patients with and without lung cryptococcosis in clinics, but few epidemiological study has been explored in this region. Here, we retrospectively reviewed the medical records of patients with CM who were admitted to two Chinese university hospitals in Southwest China in the past 5 years to investigate the discrepancies.

\section{Methods}

\section{Study population and definition}

Inclusion criteria were the following: (1) hospitalized at the First Affiliated Hospital of Army Medical University in Chongqing and the Affiliated Hospital of North Sichuan Medical College in Nanchong City of Sichuan Province, China, from January 2014 to December 2018; (2) a positive isolate of Cryptococcus neoformans from cerebrospinal fluid (CSF) culture; and (3) diagnosed with CM.

Patients with pneumonia and tuberculosis were classified as having lung infection. Sex, age, length of hospital stay, CSF profiles, brain images, underlying diseases, initial presentation, drug resistance of Cryptococcus neoformans, antifungal therapy and outcomes were recorded. The outcomes were classified as "cured", "improved", "other", "untreated", "invalid", and "death" at discharge and further classified into satisfactory (cured or improved) and unsatisfactory (the others) outcomes in accordance with previous studies $[11,16]$. (1) "Cured," no reappearance of symptoms, and 2 sequential negative CSF cultures for C. neoformans with at least a 2-week interval; (2) "Improved," no reappearance of symptoms, but without sequential negative CSF cultures for C. neoformans with at least a 2-week interval; (3) "Invalid", the symptoms were not improved.

\section{Statistical analysis}

SPSS version 17.0 (SPSS Inc., Chicago, IL) was used to analyze the data. Data are presented as the mean \pm SD or median and range. Independent Student's t-test and Mann-Whitney U test were used to compare 
parametric and nonparametric continuous variables, respectively. Categorical variables were compared using the Chi-squared test or Fisher's exact test. Then the regression equations for predicting the probability of poor prognosis of CM were established. A P-value of $<0.05$ was considered statistically significant. All analyses were conducted as 2-sided tests.

\section{Results}

\section{Demographic data}

From January 2014 to December 2018, a total of 58 patients from Southwest Hospital were included during the 5 years, and 14 (24.1\%) patients were HIV positive. A total of 40 patients from North Sichuan Medical College were included in the study, and 13 (32.5\%) patients were HIV positive. Among the 71 nonHIV CM patients, 35 (49.3\%) patients had lung disease.

Compared with that in the patients without lung infection, $\mathrm{CM}$ occurred more frequently in male $(62.9 \%$ vs. $44.4 \%$ ) and young (aged under 30 years, $31.4 \%$ vs. $16.7 \%$ ) patients with lung infection. Among CM patients without lung infection, the common initial symptoms were headache $(25 / 36,69.4 \%)$, followed by fever $(11 / 36,30.6 \%)$, vomiting $(9 / 36,25.0 \%)$, dizziness $(6 / 36,16.7 \%)$, ventosity $(6 / 36,16.7 \%)$, progressive disturbance of consciousness $(4 / 36,11.1 \%)$, vague speech, memory deterioration, and walking lability $(4 / 36,11.1 \%)$. Among CM patients with lung infection, the common initial symptoms were fever $(77.1 \%)$, headache $(77.1 \%)$, dizziness (14.3\%), vomiting (14.3\%), progressive disturbance of consciousness (17.1\%), edema of lower extremities (28.6\%), and cough and expectoration (28.6\%). Compared with CM patients without lung infection, $C M$ patients with lung infection presented more fever ( $P \bowtie 0.01)$, more edema of lower extremities and cough and expectoration (Pख0.01), less vomiting ( $14.3 \%$ vs. $25.0 \%$ ), less central nervous system symptoms and less ventosity (both $5.7 \%$ vs. $16.7 \%$ ).

The common underlying diseases, factors or complications for $\mathrm{CM}$ patients without lung infection were decompensated hepatic cirrhosis of hepatitis B $(11.1 \%)$, sepsis (11.1\%), epilepsy (11.1\%), hypertension (11.1\%), intracranial infection (16.7\%), and hydrocephalus (13.9\%). The common underlying diseases, factors or complications for $\mathrm{CM}$ patients with lung infection were intracranial infection (17.1\%), sepsis (14.3\%), nephrotic syndrome (14.3\%), systemic lupus erythematosus (17.1\%), and type II diabetes mellitus $(11.4 \%)$. There were no significant differences in underlying diseases, factors or complications between $\mathrm{CM}$ patients with and without lung infections (P凶0.05) (table 1).

\section{Laboratory data}

The positive rates of the Pandy test of CSF in CM patients with and without lung infection were both high (77.1\% vs. $72.2 \%)$, and the chloride ion and glucose levels were both decreased, while the total protein was increased in both. However, the percentage of CM patients with lung infection with WBC counts $\varangle 20 \times 10^{6} / \mathrm{L}$ was higher than that of patients without lung infection ( $45.7 \%$ vs. $\left.22.2 \%, P \llbracket 0.05\right)$. The brain 
images detected by CT or MRI showed that the percentages of ethmoid sinusitis, maxillary sinusitis, paranasal sinusitis, and otitis media in $\mathrm{CM}$ patients without lung function were higher than those in patients with lung infection (30.6\% vs. 8.6\%, P囚0.05) (table 2).

\section{Antifungal therapy and outcome}

Most of the isolated Cryptococcus neoformans from CSF in patients with and without lung infection were sensitive to itraconazole, voriconazole, fluconazole, and amphotericin B but resistance to flucytosine ( $25.7 \%$ vs. $19.4 \%$ ) (table 3 ). More CM patients with lung infection used fluconazole+amphotericin $B$ than patients without lung infection (74.3\% vs. $50.0 \%, \mathrm{P} \otimes 0.05)$. The symptoms of $\mathrm{CM}$ of most patients with and without lung infection were improved at discharge (65.7\% vs. 61.1\%) (table 4).

\section{Risk factors for poor treatment outcome of HIV negative $\mathrm{CM}$}

We included eight factors lung infection, sex, age, fever, WBC counts $₫ 20 \times 10^{6} / \mathrm{L}$, chloride ion, protein, and glucose that may impacting the prognosis of $\mathrm{CM}$ patients in the regression. Multiple regression analysis showed that WBC counts $₫ 20 \times 10^{6} / \mathrm{L}$ was significantly associated with treatment outcome $(O R=0.01$, $95 \% \mathrm{Cl}=0-0.833, \mathrm{P}=0.041)$, and lung infection showed a tendency of association with treatment outcome $(\mathrm{OR}=0.026,95 \% \mathrm{Cl}=0.001-1.173, \mathrm{P}=0.06)($ table 5$)$.

\section{Discussion}

It is generally known that $\mathrm{CM}$ is an opportunistic infection in HIV-positive patients, but it also occurs in HIV-negative patients. In a population-based study in the United States, the incidence of cryptococcosis among HIV-negative patients was close to half of the overall cases reported [8]. In the current study, $72.4 \%$ (71/98) of the patients were HIV negative, which may be because the patients were transferred to a professional hospital once HIV was discovered.

Lung infection affects many people in China, and our study showed a high proportion (49.3\%) of CM patients with lung infection. The clinical characteristics of $\mathrm{CM}$ varied depending on the underlying conditions, such as virus infection, immune state, fungal species or lineage differences, and age $[15,17]$. In the current studies, the overall sex and age in $\mathrm{CM}$ patients with and without lung infection were not significantly different; however, $\mathrm{CM}$ occurred more frequently in male and younger patients (aged $\leq 30$ years) with lung infection than in patients without lung infection. In a United States series of over 300 HIV-negative patients with cryptococcal infection, half had CNS involvement, and of these, $24 \%$ had chronic liver, kidney or lung disease; $16 \%$ had a malignancy; and $15 \%$ had received a solid organ transplant [18]. However, in our data, among 71 HIV-negative patients with $\mathrm{CM}$, half had lung infection, followed by intracranial infection ( $16.9 \%)$, systemic lupus erythematosus $(12.7 \%)$, sepsis $(12.7 \%)$, nephrotic syndrome (9.9\%), type II diabetes mellitus (9.9\%), hypertension (9.9\%), epilepsy (8.5\%), and 
decompensated hepatic cirrhosis of hepatitis B (8.5\%), which were different from the previous studies. Patients with CM presented with neurological symptoms, most typically headache and altered mental status, as well as with fever, nausea and vomiting. In the current studies, the main symptoms of patients were neurological symptoms, such as headache, followed by fever, vomiting, dizziness, ventosity, progressive disturbance of consciousness, vague speech, memory deterioration, and walking lability, and the symptoms in the two groups had no significant differences.

A large proportion of HIV-negative patients may have a marked systemic inflammatory response and hydrocephalus [17]. In our data, patients with lung infection presented with a higher proportion of fever, cough and expectoration, a lower proportion of noncentral nervous system symptoms, and a higher percentage of WBC counts in CSF $₫ 20 \times 10^{6} / \mathrm{L}$ than patients without lung infection, which may suggest a higher inflammatory response of the brain in patients with lung infection than in patients without lung infection. However, in the current studies, only $9.9 \%$ of patients had hydrocephalus. In addition, patients with lung infection had less vomiting, ventosity, ethmoid sinusitis, maxillary sinusitis, paranasal sinusitis, and otitis media than patients without lung infection, and $28.6 \%$ of patients had edema of lower extremities; clinicians should pay attention to this symptom.

In contrast to the rare resistance of Cryptococcus neoformans to flucytosine that showed a baseline fluconazole resistance rate of $12 \%$ in previous studies [19,20], our results showed that Cryptococcus neoformans isolates from CSF were sensitive to fluconazole but resistant to flucytosine, with a resistance rate of $22.5 \%$. Most of the recommendations for the management of non-HIV CM patients are extrapolated from HIV studies, among which the combination therapy of amphotericin B and flucytosine for the treatment of CM was the most commonly used in clinical trials [21, 22]. However, only $11.3 \%$ of patients were treated with amphotericin B + flucytosine in our data; most $(62.0 \%) \mathrm{CM}$ patients used fluconazole + amphotericin B due to the drug resistance rate of Cryptococcus neoformans to flucytosine. Outcomes for patients with HIV-associated cryptococcal meningitis in Africa suggested a 3-month mortality of $70 \%$ [17]. In prospective research studies, for patients treated with fluconazole, mortality at 10 weeks was $50-60 \%[23,24]$. In the current studies, $67.6 \%$ of patients had satisfactory results at discharge, which was consistent with previous studies. In HIV-negative individuals, altered mental status, markers of a poor inflammatory response, and low CSF white cell count have been linked with poor prognosis [25]. According to our results, the mortality of patients in the lung infection group was increased, which was consistent with the results showing a reduced CSF white cell count, furthermore, multivariable analyses showed that WBC counts $₫ 20 \times 10^{6} / \mathrm{L}$ was the risk factor of treatment outcome.

This study has some limitations. First, the study was performed in only two hospitals in Southwest China. Second, we only investigated the recent 5-year clinical records of CM patients, and the number of patients was relatively small. Third, this investigation is a retrospective study, some Cryptococcus neoformans isolates with unique genotype have higher virulence or azole-resistance, we could not provide genotype data of the related Cryptococcus neoformans isolates in the study, and we could not obtain the long-term outcome of patients. Further multicenter studies are needed to confirm our results and investigate more significant factors to improve the diagnosis and treatment of CM patients with lung infection. 


\section{Conclusions}

In conclusion, we found that compared with the patients without lung infection, male and younger patients with lung infection presented with $\mathrm{CM}$ more frequently, with more fever, edema of lower extremities and cough and expectoration; less central nervous system symptoms, vomiting and ventosity; higher percentage of WBC counts $₫ 20 \times 10^{6} / \mathrm{L}$; and lower percentage of ethmoid sinusitis, maxillary sinusitis, paranasal sinusitis, and otitis media. Clinicians must consider the divergences in the diagnosis of $\mathrm{CM}$ in patients with lung infection.

\section{Abbreviations}

CM: cryptococcal meningitis; CNS: central nervous system; CSF: cerebrospinal fluid; HIV: human immunodeficiency virus; WBC: white blood cell

\section{Declarations}

\section{Acknowledgments}

Not applicable.

\section{Author Contributions}

L. C. and P. X. conceived the study; M. Y., F. S., F. L., W. F., Q. Y., and Y. W. searched the data, M. Y. and L. C. performed the analyses, L. C. prepared the first manuscript draft, all authors reviewed and revised the manuscript.

\section{Funding}

This work is supported by the Sichuan Science and Technology Program (2018JY0415).

\section{Availability of data and materials}

The datasets used and / or analyzed during the current study are available from the corresponding author on reasonable request.

\section{Ethics approval and consent to participate}

This study was approved by the Ethics Committee of the First Affiliated Hospital of Army Medical University and was in compliance with the Declaration of Helsinki. No administrative permission were 
required to access data.

\section{Consent for publication}

Not applicable.

\section{Competing interests}

The authors declare that they have no conflicts of interest.

\section{References}

1.Elsegeiny W, Marr KA, Williamson PR: Immunology of Cryptococcal Infections: Developing a Rational Approach to Patient Therapy. Front Immunol 2018, 9:651.

2.Rajasingham R, Smith RM, Park BJ, Jarvis JN, Govender NP, Chiller TM, Denning DW, Loyse A, Boulware DR: Global burden of disease of HIV-associated cryptococcal meningitis: an updated analysis. Lancet Infect Dis 2017, 17(8):873-881.

3.Pyrgos V, Seitz AE, Steiner CA, Prevots DR, Williamson PR: Epidemiology of cryptococcal meningitis in the US: 1997-2009. PLoS One 2013, 8(2):e56269.

4.Kiertiburanakul S, Wirojtananugoon S, Pracharktam R, Sungkanuparph S: Cryptococcosis in human immunodeficiency virus-negative patients. Int J Infect Dis 2006, 10(1):72-78.

5.Brizendine KD, Baddley JW, Pappas PG: Predictors of mortality and differences in clinical features among patients with Cryptococcosis according to immune status. PLoS One 2013, 8(3):e60431.

6.Alanio A, Vernel-Pauillac F, Sturny-Leclere A, Dromer F: Cryptococcus neoformans host adaptation: toward biological evidence of dormancy. MBio 2015, 6(2).

7.Jarvis JN, Wainwright $\mathrm{H}$, Harrison TS, Rebe K, Meintjes G: Pulmonary cryptococcosis misdiagnosed as smear-negative pulmonary tuberculosis with fatal consequences. Int J Infect Dis 2010, 14 Suppl 3:e310312.

8.George IA, Spec A, Powderly WG, Santos CAQ: Comparative Epidemiology and Outcomes of Human Immunodeficiency virus (HIV), Non-HIV Non-transplant, and Solid Organ Transplant Associated Cryptococcosis: A Population-Based Study. Clin Infect Dis 2018, 66(4):608-611.

9.Guo LY, Liu LL, Liu Y, Chen TM, Li SY, Yang YH, Liu G: Characteristics and outcomes of cryptococcal meningitis in HIV seronegative children in Beijing, China, 2002-2013. BMC Infect Dis 2016, 16(1):635. 
10.Hung CW, Lin WC, Chang WN, Su TM, Kung CT, Tsai NW, Wang HC, Huang CC, Cheng BC, Su YJ et al: Risk factors and outcomes of cerebrospinal fluid overdrainage in HIV-negative patients with cryptococcal meningitis after the ventriculoperitoneal shunting procedure. J Microbiol Immunol Infect 2018, 51(4):545-551.

11.Li M, Chen Z, Xu L, Gan Z, Peng F, Liu J: A Comparison of the Clinical Characteristics and Outcomes of Cryptococcal Meningitis in HIV-negative Individuals With and Without Immunosuppression. Neurologist 2019, 24(1):1-5.

12.Naik KR, Saroja AO, Doshi DK: Hospital-based Retrospective Study of Cryptococcal Meningitis in a Large Cohort from India. Ann Indian Acad Neurol 2017, 20(3):225-228.

13.Qu J, Zhou T, Zhong C, Deng R, Lu X: Comparison of clinical features and prognostic factors in HIVnegative adults with cryptococcal meningitis and tuberculous meningitis: a retrospective study. BMC Infect Dis 2017, 17(1):51.

14.Zhong YH, Tan F, Li M, Liu J, Wang X, Yuan Y, Zhong XF, Peng FH: Comparisons of presentations and outcomes of cryptococcal meningitis between patients with and without hepatitis $B$ virus infection. Int $J$ Infect Dis 2014, 20:31-36.

15.Tsai WC, Lien CY, Lee JJ, Hsiao WC, Huang CR, Tsai NW, Chang CC, Lu CH, Chang WN: The clinical characteristics and therapeutic outcomes of cryptococcal meningitis in elderly patients: a hospital-based study. BMC Geriatr 2019, 19(1):91.

16.Lu CH, Chang WN, Chang HW, Chuang YC: The prognostic factors of cryptococcal meningitis in HIVnegative patients. J Hosp Infect 1999, 42(4):313-320.

17.Williamson PR, Jarvis JN, Panackal AA, Fisher MC, Molloy SF, Loyse A, Harrison TS: Cryptococcal meningitis: epidemiology, immunology, diagnosis and therapy. Nat Rev Neurol 2017, 13(1):13-24.

18.Pappas PG, Perfect JR, Cloud GA, Larsen RA, Pankey GA, Lancaster DJ, Henderson H, Kauffman CA, Haas DW, Saccente M et al: Cryptococcosis in human immunodeficiency virus-negative patients in the era of effective azole therapy. Clin Infect Dis 2001, 33(5):690-699.

19.Smith KD, Achan B, Hullsiek KH, McDonald TR, Okagaki LH, Alhadab AA, Akampurira A, Rhein JR, Meya DB, Boulware DR et al: Increased Antifungal Drug Resistance in Clinical Isolates of Cryptococcus neoformans in Uganda. Antimicrob Agents Chemother 2015, 59(12):7197-7204.

20.Bongomin F, Oladele RO, Gago S, Moore CB, Richardson MD: A systematic review of fluconazole resistance in clinical isolates of Cryptococcus species. Mycoses 2018, 61(5):290-297.

21. Henao-Martinez AF, Chastain DB, Franco-Paredes C: Treatment of cryptococcosis in non-HIV immunocompromised patients. Curr Opin Infect Dis 2018, 31(4):278-285. 
22.Vu K, Garcia JA, Gelli A: Cryptococcal Meningitis and Anti-virulence Therapeutic Strategies. Front Microbiol 2019, 10:353.

23.Phillips P, Galanis E, MacDougall L, Chong MY, Balshaw R, Cook VJ, Bowie W, Steiner T, Hoang L, Morshed $\mathrm{M}$ et al: Longitudinal clinical findings and outcome among patients with Cryptococcus gattii infection in British Columbia. Clin Infect Dis 2015, 60(9):1368-1376.

24.Gaskell KM, Rothe C, Gnanadurai R, Goodson P, Jassi C, Heyderman RS, Allain TJ, Harrison TS, Lalloo DG, Sloan DJ et al: A prospective study of mortality from cryptococcal meningitis following treatment induction with 1200 mg oral fluconazole in Blantyre, Malawi. PLoS One 2014, 9(11):e110285.

25.Chen SC, Slavin MA, Heath CH, Playford EG, Byth K, Marriott D, Kidd SE, Bak N, Currie B, Hajkowicz K et al: Clinical manifestations of Cryptococcus gattii infection: determinants of neurological sequelae and death. Clin Infect Dis 2012, 55(6):789-798.

\section{Tables}

Table 1 Demographic and clinical features in HIV-negative cryptococcal meningitis patients with and without lung diseases 


\begin{tabular}{|c|c|c|c|}
\hline Variables & $\begin{array}{c}\text { Without lung } \\
\text { infection }(n=36)\end{array}$ & $\begin{array}{c}\text { With lung } \\
\text { infection }(n=35)\end{array}$ & $\begin{array}{l}P \text { - } \\
\text { value }\end{array}$ \\
\hline Sex & & & 0.12 \\
\hline Male & $16(44.4 \%)$ & $22(62.9 \%)$ & \multirow{4}{*}{0.30} \\
\hline $\begin{array}{l}\text { Female } \\
\text { Aqe (vears) }\end{array}$ & $20(55.6 \%)$ & $13(37.1 \%)$ & \\
\hline$\leq 30$ & $6(16.7 \%)$ & $11(31.4 \%)$ & \\
\hline $\begin{array}{l}\overline{3} 1-60 \\
\square 60\end{array}$ & $\begin{array}{l}22(61.1 \%) \\
8(22.2 \%)\end{array}$ & $\begin{array}{l}16(45.7 \%) \\
8(22.9 \%)\end{array}$ & \\
\hline Length of hospital stay (d) & $32.7(18.6,46.7)$ & $36.2(22.8 .49 .7)$ & 0.49 \\
\hline \multicolumn{4}{|l|}{ Presenting symptoms and signs } \\
\hline Fever & $11(30.6 \%)$ & $27(77.1 \%)$ & 0.001 \\
\hline Headache & $25(69.4 \%)$ & $27(77.1 \%)$ & 0.46 \\
\hline Dizziness & $6(16.7 \%)$ & $5(14.3 \%)$ & 0.78 \\
\hline Vomiting & $9(25.0 \%)$ & $5(14.3 \%)$ & 0.26 \\
\hline Vague speech, memory deterioration, & $4(11.1 \%)$ & $2(5.7 \%)$ & 0.70 \\
\hline Progressive disturbance of & $4(11.1 \%)$ & $6(17.1 \%)$ & 0.70 \\
\hline consciousness & & & \\
\hline No central nervous system symptoms & $6(16.7 \%)$ & $2(5.7 \%)$ & 0.28 \\
\hline $\begin{array}{l}\text { Ventosity } \\
\text { Edema of lower extremities }\end{array}$ & $6 \underset{0}{(16.7 \%)}$ & $\begin{array}{l}2(5.7 \%) \\
10(28.6 \%)\end{array}$ & 0.28 \\
\hline Cough and expectoration & 0 & $10(28.6 \%)$ & 0.001 \\
\hline \multicolumn{4}{|l|}{ Underlying diseases, factors or } \\
\hline $\begin{array}{l}\text { complications } \\
\text { Decompensated hepatic cirrhosis of }\end{array}$ & $4(11.1 \%)$ & $2(5.7 \%)$ & 0.70 \\
\hline $\begin{array}{l}\text { nepatitis B } \\
\text { Severe chronic hepatitis B }\end{array}$ & $2(5.6 \%)$ & 0 & 0.49 \\
\hline Sepsis & $4(11.1 \%)$ & $5(14.3 \%)$ & 0.96 \\
\hline Epilepsy & $4(11.1 \%)$ & $2(5.7 \%)$ & 0.70 \\
\hline Hypertension & $4(11.1 \%)$ & $3(8.6 \%)$ & 1.00 \\
\hline Upper gastrointestinal bleeding & $2(5.6 \%)$ & 0 & 0.49 \\
\hline Hypokalemia & $3(8.3 \%)$ & $2(5.7 \%)$ & 1.00 \\
\hline Intracranial infection & $6(16.7 \%)$ & $6(17.1 \%)$ & 0.96 \\
\hline Nephrotic syndrome & $2(5.6 \%)$ & $5(14.3 \%)$ & 0.40 \\
\hline Systemic lupus erythematosus & $3(8.3 \%)$ & $6(17.1 \%)$ & 0.45 \\
\hline Chronic transplantation kidney disease & $2(5.6 \%)$ & 0 & 0.49 \\
\hline Cerebral infarction & $3(8.3 \%)$ & $3(8.6 \%)$ & 1.00 \\
\hline Ventriculoperitoneal shunt & $3(8.3 \%)$ & $2(5.7 \%)$ & 1.00 \\
\hline Hypoproteinemia & $2(5.6 \%)$ & $3(8.6 \%)$ & 0.97 \\
\hline Myasthenia gravis & $2(5.6 \%)$ & 0 & 0.49 \\
\hline Rheumatic arthritis & $2(5.6 \%)$ & 0 & 0.49 \\
\hline Type II diabetes mellitus & $3(8.3 \%)$ & $4(11.4 \%)$ & 0.97 \\
\hline Thrombocytopenic purpura & $2(5.6 \%)$ & 0 & 0.49 \\
\hline Herpes zoster & $2(5.6 \%)$ & 0 & 0.49 \\
\hline Gallbladder carcinoma with liver & 0 & $2(5.7 \%)$ & 0.46 \\
\hline $\begin{array}{l}\text { metastasis } \\
\text { Non-Hodgkin's lymphoma }\end{array}$ & $1(2.8 \%)$ & 0 & 1.00 \\
\hline
\end{tabular}

Table 2 Cerebrospinal fluid characteristics and brain images of patients with CM in HIVnegative cryptococcal meningitis patients with and without lung diseases 


\begin{tabular}{|c|c|c|c|}
\hline Variables & $\begin{array}{c}\text { Without lung } \\
\text { infection }(n=36)\end{array}$ & $\begin{array}{c}\text { With lung } \\
\text { infection }(n=35)\end{array}$ & $\begin{array}{c}P- \\
\text { value }\end{array}$ \\
\hline \multicolumn{4}{|l|}{ Cerebrospinal fluid profiles } \\
\hline Pandy test (positive) & $26(72.2 \%)$ & \multirow{2}{*}{$\begin{array}{c}27(77.1 \%) \\
0.105(-0.001 \\
0.211)\end{array}$} & \multirow{2}{*}{$\begin{array}{l}0.63 \\
0.30\end{array}$} \\
\hline WBC counts $\left(\times 10^{9} / \mathrm{L}\right)$ & $0.12(0.05,0.18)$ & & \\
\hline$\square 20 \times 10^{6} / \mathrm{L}$ & $8(22.2 \%)$ & \multirow{2}{*}{$\begin{array}{c}16(45.7 \%) \\
118.1 \pm 5.4 \\
1.04(0.39 \\
1.69)\end{array}$} & 0.036 \\
\hline $\begin{array}{l}\text { Chloride ion }(120-130 \mathrm{mmol} / \mathrm{L}) \\
\text { Protein }(0.15-0.45 \mathrm{~g} / \mathrm{L})\end{array}$ & $\begin{array}{c}115.6 \pm 5.5 \\
1.17(0.55,1.78)\end{array}$ & & $\begin{array}{l}0.19 \\
0.71\end{array}$ \\
\hline $\begin{array}{l}\square 0.45 \mathrm{~g} / \mathrm{L} \\
\text { Glucose }(2.5-4.5 \mathrm{mmol} / \mathrm{L}) \\
\square 2.5 \mathrm{mmol} / \mathrm{L} \\
\text { Adenylate deaminase }(0-15 \mathrm{U} / \mathrm{L})\end{array}$ & $\begin{array}{c}28(77.8 \%) \\
1.74 \pm 1.09 \\
30(83.3 \%) \\
2.31(1.34,3.28)\end{array}$ & $\begin{array}{c}1.69) \\
22(62.9 \%) \\
1.72 \pm 1.27 \\
28(80.0 \%) \\
2.18(1.58,2.78)\end{array}$ & $\begin{array}{l}0.17 \\
0.66 \\
0.72 \\
0.63\end{array}$ \\
\hline Brain images (CT/MRI) & & & \\
\hline $\begin{array}{l}\text { Cerebral ischemia/infarction } \\
\text { Meningeal enhancement }\end{array}$ & $\begin{aligned} 16 & (44.4 \%) \\
3 & (8.3 \%)\end{aligned}$ & $\begin{array}{c}14(40.0 \%) \\
0\end{array}$ & $\begin{array}{l}0.71 \\
0.25\end{array}$ \\
\hline Hydrocephalus & $5(13.9 \%)$ & $2(5.7 \%)$ & 0.45 \\
\hline Ethmoid sinusitis, maxillary sinusitis, & $11(30.6 \%)$ & $3(8.6)$ & 0.02 \\
\hline $\begin{array}{l}\text { paranasal } \\
\text { Normal }\end{array}$ & $8(22.2 \%)$ & $7(20.0 \%)$ & 0.82 \\
\hline
\end{tabular}

WBC, white blood cell

Table 3 Drug resistance of Cryptococcus neoformans

\begin{tabular}{|c|c|c|c|c|c|c|c|c|c|}
\hline \multirow{2}{*}{$\begin{array}{l}\text { Antifungal } \\
\text { agent }\end{array}$} & \multicolumn{4}{|c|}{ Without lung infection $(\mathrm{n}=36)$} & \multicolumn{4}{|c|}{ With lung infection $(n=35)$} & \multirow{2}{*}{$\begin{array}{c}P \text { - } \\
\text { value }\end{array}$} \\
\hline & Sensitive & Intermediary & Resistance & $\begin{array}{c}\text { Not } \\
\text { available } \\
\end{array}$ & Sensitive & Intermediary & Resistance & $\begin{array}{c}\text { Not } \\
\text { available }\end{array}$ & \\
\hline Itraconazole & $\begin{array}{c}11 \\
(30.6 \%)\end{array}$ & $1(2.8 \%)$ & 0 & $24(66.7 \%)$ & $\begin{array}{c}12 \\
(34.3 \%)\end{array}$ & 0 & 0 & $23(65.7 \%)$ & 0.59 \\
\hline Voriconazole & $\begin{array}{c}12 \\
(33.3 \%)\end{array}$ & 0 & 0 & $24(66.7 \%)$ & $\begin{array}{c}12 \\
(34.3 \%)\end{array}$ & 0 & 0 & $23(65.7 \%)$ & 0.93 \\
\hline Fluconazole & $\begin{array}{c}11 \\
(30.6 \%)\end{array}$ & $1(2.8 \%)$ & 0 & $24(66.7 \%)$ & $\begin{array}{c}14 \\
(40.0 \%)\end{array}$ & 0 & 0 & $21(60.0 \%)$ & 0.46 \\
\hline flucytosine & $4(11.1 \%)$ & $3(8.3 \%)$ & $7(19.4 \%)$ & $22(61.1 \%)$ & $5(14.3 \%)$ & 0 & $9(25.7 \%)$ & $21(60.0 \%)$ & 0.34 \\
\hline Amphotericin B & $\begin{array}{c}12 \\
(33.3 \%) \\
\end{array}$ & 0 & 0 & $24(66.7 \%)$ & $\begin{array}{c}11 \\
(31.4 \%) \\
\end{array}$ & 0 & 0 & $24(68.6 \%)$ & 0.86 \\
\hline
\end{tabular}

Table 4 Antifungal therapy and outcome 


\begin{tabular}{lccc}
\hline Treatment & Without lung infection & With lung infection \\
$(\mathrm{n}=36)$ & $\begin{array}{c}P- \\
(\mathrm{n}=35)\end{array}$ & value \\
\hline Fluconazole alone & $4(11.1 \%)$ & $4(11.4 \%)$ & 1.00 \\
Amphotericin B alone & $10(27.8 \%)$ & $4(11.4 \%)$ & 0.08 \\
Fluconazole+amphotericin & $18(50.0 \%)$ & $26(74.3 \%)$ & 0.035 \\
B & & $2(5.7 \%)$ & 0.28 \\
Amphotericin B+flucytosine & $6(16.7 \%)$ & 0 & 1.00 \\
Fluconazole+flucytosine & $1(2.8 \%)$ & $10(28.6 \%)$ & 0.66 \\
Did not receive antifungal & $12(33.3 \%)$ & & \\
therapy & & $21(60.0 \%)$ & 0.54 \\
Outcome & $19(52.8 \%)$ & $2(5.7 \%)$ & 1.00 \\
Improved & $3(8.3 \%)$ & $4(11.4 \%)$ & 0.77 \\
Cured & $6(16.7 \%)$ & $5(14.3 \%)$ & 0.39 \\
Invalid & $8(22.2 \%)$ & $3(8.6 \%)$ & 0.12 \\
Others & 0 & & \\
Death & & & \\
\hline
\end{tabular}

Table 5 Risk factors associated with poor prognosis of HIV negative cryptococcal meningitis (CM)

\begin{tabular}{lccc}
\hline Variables & Odds ratio & $95 \%$ CI & $P$-value \\
\hline Lung infection & 0.026 & $0.001-1.173$ & 0.06 \\
Male & 4.939 & $0.368-66.343$ & 0.228 \\
Age & 0.922 & $0.841-1.01$ & 0.081 \\
Fever & 3.663 & $0.26-51.674$ & 0.336 \\
WBC counts $\geq 20 \times 10^{6} / \mathrm{L}$ & 0.01 & $0-0.833$ & 0.041 \\
Chloride ion & 1.266 & $0.888-1.806$ & 0.193 \\
Protein & 0.946 & $0.345-2.593$ & 0.915 \\
Glucose & 0.395 & $0.096-1.633$ & 0.2 \\
\hline
\end{tabular}

WBC, white blood cell 